\title{
Enhanced surveillance of acute hepatitis $B$ and $C$ in four health regions in Canada, 1998 to 1999
}

Shimian Zou MD PhD ${ }^{1}$, Jun Zhang MD MSc ${ }^{1}$, Martin Tepper MD FRCPC ${ }^{1}$, Antonio Giulivi MD FRCPC ${ }^{1}$, Beverley Baptiste RN BSCN${ }^{2}$, Gerry Predy MD FRCPC ${ }^{2}$, Darlene Poliquin RN BScN ${ }^{3}$, Manon Morin RN BScN ${ }^{3}$, Donna Jones RN BScN ${ }^{4}$, Joy Loewen $\mathrm{RN} \mathrm{BSCN}^{4}$, Margaret Ogonowski RN BN ${ }^{5}$, Stephen Moses MD MPH ${ }^{5}$, Lawrence Elliott MD FRCPC ${ }^{5}$

S Zou, J Zhang, M Tepper, et al. Enhanced surveillance of acute hepatitis B and acute hepatitis C in four health regions in Canada, 1998 to 1999. Can J Infect Dis 2001;12(6):357-363.

OBJECTIVE: To assess the incidence and risk factors for acute hepatitis B and acute hepatitis C in a defined Canadian population.

PATIENTS AND METHODS: An enhanced surveillance system was established in October 1998 to identify cases of acute hepatitis $\mathrm{B}$ and $\mathrm{C}$ infections in four regions in Canada, with a total population of approximately 3.2 million people. Information on demographic and clinical characteristics, laboratory results and potential risk factors was collected using predefined questionnaires.

RESULTS: A total of 79 cases of acute hepatitis B and 102 cases of acute hepatitis C were identified from October 1998 to December 1999, resulting in an incidence rate of 2.3 and 2.9/100,000 person-years, respectively. Males had higher incidence rates than females. The incidence of acute hepatitis B peaked at age 30 to 39 years for both males and females, whereas acute hepatitis C peaked at 30 to 39 years for males and 15 to 29 years for females. At least $34 \%$ of acute hepatitis B and $63 \%$ of acute hepatitis C were associated with injection drug use. Persons who were 15 to 39 years of age were more likely to report injection drug use as a risk factor. Heterosexual contact was reported to be a risk factor for $36.6 \%$ of acute hepatitis B cases and $3.5 \%$ of acute hepatitis C cases.

CONCLUSIONS: The surveillance provides national incidence estimates of clinically recognized acute hepatitis B and C. Both hepatitis B and C are important public health threats to Canadians. Prevention efforts for both diseases should focus on injection drug use, especially for people aged 15 to 39 years. Risky sexual behaviour is also a major concern in prevention of hepatitis B in Canada.

Key Words: Canadians; Hepatitis B; Hepatitis C; Incidence; Risk factors; Surveillance

Pour le résumé, voir page suivante

\footnotetext{
${ }^{1}$ Centre for Infectious Disease Prevention and Control, Health Canada, Ottawa, Ontario; ${ }^{2}$ Capital Health, Edmonton, Alberta; ${ }^{3}$ Ottawa-Carleton Health Department, Ottawa, Ontario; ${ }^{4}$ Calgary Regional Health Authority, Calgary, Alberta; ${ }^{5}$ Manitoba Health, Winnipeg, Manitoba Correspondence and reprints: Dr Shimian Zou, Bloodborne Pathogens Division, Bureau of Infectious Diseases, Centre for Infectious Disease Prevention and Control, Postal Locator 0601E2, Ottawa, Ontario, Canada K1A OL2. Telephone 613-946-8819, fax 613-952-6668, e-mailshimian_zou@hc-sc.gc.ca

Received for publication May 23, 2000. Accepted August 25, 2000
} 


\section{Surveillance accrue de I'hépatite $B$ et de l'hépatite $C$ dans quatre régions sanitaires du Canada, 1998 à 1999}

OBJECTIF : Mesurer l'incidence et évaluer les facteurs de risque liés à l'hépatite B et à l'hépatite C aiguës au sein d'une pop-
ulation canadienne définie.
PATIENTS ET MÉTHODES : Un système de surveillance améliorée a été mis sur pied en octobre 1998 pour identifier les cas
d'hépatite B et d'hépatite C aiguës dans quatre régions du Canada représentant une population totale d'environ 3,2 millions
de personnes. Les renseignements démographiques et les caractéristiques cliniques, les résultats des analyses de laboratoire
et les facteurs de risque potentiel figurent parmi les données recueillies à l'aide d'un questionnaire prédéfini.
RÉSULTATS : En tout, 79 cas d'hépatite B aiguë et 102 cas d'hépatite C aiguë ont été recensés entre octobre 1998 et décem-
bre 1999 , représentant une incidence de 2,3 et de $2,9 / 100$ o00 années-personnes, respectivement. L'incidence a été plus
élevée chez les hommes que chez les femmes. L'incidence de l'hépatite B aiguë a été à son maximum chez les sujets de 30 à
39 ans, tant chez les hommes que chez les femmes, alors que celle de l'hépatite C aiguë, l'a été chez les hommes de 30 à
39 ans et chez les femmes de 15 à 29 ans. Au moins $34 \%$ des cas d'hépatite B aiguë et $63 \%$ des cas d'hépatite C aiguë
étaient associés à l'utilisation de drogues par injection. Les personnes de 15 à 39 ans étaient plus susceptibles de mention-
ner la consommation de drogues par injection comme facteur de risque. Les contacts hétérosexuels ont été signalés comme
facteurs de risque chez $36,6 \%$ des sujets atteints d'hépatite B aiguë et chez $3,5 \%$ des sujets atteints d'hépatite C aiguë.
concLUSION : La surveillance donne une estimation de l'incidence nationale des cas d'hépatite B et d'hépatite C aiguë clin-
iquement reconnus. L'hépatite B et l'hépatite C représentent d'importantes menaces pour la santé publique au Canada. Les
efforts en vue de prévenir ces deux maladies devraient porter davantage sur la problématique des toxicomanies, spéciale-
ment chez les 15 à 39 ans. Le comportement sexuel à risque constitue un autre important problème en matière de préven-
tion de l'hépatite B au Canada.

$\mathrm{H}_{\mathrm{c}}^{\mathrm{e}}$ epatitis B and C are important public health concerns in Canada. It was suggested that over 100,000 Canadians are infected with hepatitis B virus (HBV) (1) and approximately 240,000 are infected with hepatitis C virus (HCV) (2). Risk factors associated with transmission of HBV and HCV in Canada have been examined in various studies and summarized by Tepper and Gully $(3,4)$. Two recent studies also addressed factors associated with acquisition of HBV among street youth (5) and HCV in blood donors (6). Risk factors that have been described for HBV transmission include injection drug use (IDU), multiple sex partners, sexual contact with hepatitis carriers, high risk homosexual activity of men, and possibly tattooing and body piercing $(3,5)$. Risk factors for HCV infection are IDU, history of blood transfusion or receipt of blood products before 1990, and sexual contact with an injection drug user. Occupational blood exposure, history of surgery and hospitalization or institutionalization may be related to an increased risk of acquiring $\mathrm{HCV}$ in Canada $(4,6)$.

Hepatitis B has been reportable in all jurisdictions since 1969 (3), and hepatitis C became reportable across the country in all jurisdictions at the beginning of 1999 (unpublished data, Zou et al) through the National Notifiable Disease Reporting System (NNDR) (7). However, the ability to describe correctly the epidemiology of acute hepatitis B and C is affected by the nature of the infections (eg, mostly silent when first acquired), the inconsistency of reporting practices in different jurisdictions, and the lack of information on risk factors associated with the transmission of hepatitis B and C. In particular, for hepatitis $C$ (8-10), the asymptomatic nature in most infected cases, the high frequency of chronicity and the lack of a single test to differentiate acute from remote infections may have resulted in most reported cases being remotely acquired infections. This routine surveillance alone cannot meet public health surveillance needs for hepatitis B and $\mathrm{C}$ in Canada.

To obtain a more appropriate assessment of the current infection level of hepatitis B and C, a population-based enhanced surveillance project was initiated in four health regions (Calgary, Alberta; Edmonton, Alberta; OttawaCarleton, Ontario; and Winnipeg, Manitoba) in 1998. The surveillance project also investigated risk factors associated with transmission to provide fundamental information for effective prevention and control of hepatitis $B$ and $C$ in the Canadian population. This report summarizes the methods of this surveillance system and reports findings from October 1998 to December 1999.

\section{PATIENTS AND METHODS}

Population under surveillance: The enhanced surveillance was started first in the Capital Health Region in Edmonton and the Ottawa-Carleton Health Department on October 1, 1998. On January 1, 1999, the Calgary Regional Health Authority, and Manitoba Health and the Winnipeg Regional Health Authority joined the surveillance project. The four health regions (Edmonton, Calgary, Ottawa-Carleton and Winnipeg) had a population of $801,714,907,670,916,481$, and 644,382 , respectively, with a total population of approximately 3.2 million people.

Operating procedure: A consensus protocol and standardized case definitions were developed, and used by all health regions involved in the enhanced surveillance. Each of the four health regions assigned one or more investigators to this surveillance. At the beginning of this surveillance, the investigator(s) in each health region informed physicians and laboratories in their jurisdiction of this enhanced surveillance. Laboratories that were performing confirmatory testing for hepatitis $\mathrm{B}$ or $\mathrm{C}$ in each jurisdiction either automatically reported or were contacted regularly to ask for new- 
ly identified hepatitis B and C cases, their laboratory test results and other related information. Physicians of all newly identified hepatitis B and C cases were contacted to inquire about clinical symptoms and laboratory testing results. For hepatitis patients who were symptomatic but tested negative for HBV and HCV at the onset of their illness, all physicians were also recommended to order a follow-up test for antibody against $\mathrm{HCV}$ (anti-HCV) three months or later after onset of the illness.

Furthermore, newly identified hepatitis B and C cases were asked to participate in the study through an interview process (except for those remotely acquired hepatitis B cases who were first-generation immigrants from endemic areas, eg, South East Asia and Africa). Informed consent was sought from each patient before the case interview, using a predefined consent form. Only patients who gave their consent were interviewed. Predefined Epi Info (11) questionnaires, one for hepatitis B and the other for hepatitis C, were used for investigation of all cases identified in all four health regions.

Case definition: Confirmed acute $\mathrm{HBV}$ and $\mathrm{HCV}$ infections were defined as cases that met the following clinical case definition and were laboratory confirmed. The clinical case definition is an acute illness with the discrete onset of symptoms (eg, nausea, malaise, fatigue, dark urine, loss of appetite), jaundice and elevated serum aminotransferase levels. The laboratory criteria for acute HBV infection include serum aminotransferase (alanine aminotransferase/asparate aminotransferase) levels 2.5 times higher than the upper limit of normal and hepatitis B surface antigen (HBsAg) positive (or immunoglobulin [Ig] $\mathrm{M}$ antihepatitis $\mathrm{B}$ core $[\mathrm{HBC}]$ positive, if performed) and IgM antihepatitis A virus (HAV) negative (if performed). For acute HCV infection, the laboratory criteria are serum aminotransferase levels 2.5 times greater than the upper limit of normal, IgM anti-HAV negative and HBsAg negative (or IgM anti-HBc negative, if completed), and anti-HCV positive (confirmed by a supplemental test). A case of HCV infection was also classified as an acute case if seroconversion could be determined, regardless of presence of symptoms or of other test results. Here, seroconversion referred to a change in anti-HCV status from negative in the first test to positive in the follow-up test three months or later (up to 12 months) after the first test.

Remotely acquired HBV and HCV infections or those referred to as 'unconfirmed' (confirmed as infected cases but not confirmed as acute or remote infections) were defined as: hepatitis B cases that do not meet the above definition for a confirmed acute case but had laboratory evidence of current HBV infection (eg, HBsAg positive); and hepatitis C cases that do not meet the above definition for a confirmed acute case but had laboratory evidence of current HCV infection (eg, confirmed anti-HCV positive).

Data collection: Information collected through the enhanced surveillance included demographic and clinical characteristics, laboratory test results and potential risk factors. Efforts were made to check for accuracy and to eliminate any dupli- cation. Completed questionnaires were transferred to the Centre for Infectious Disease Prevention and Control (formerly known as the Laboratory Centre for Disease Control) in an electronic format that did not contain names or other personal identifiers through which individual patients could be identified.

For hepatitis B, potential risk factors collected include (in order by a mix of transmission efficiency, importance and other considerations): IDU, drug snorting, blood transfusion, receipt of blood products (eg, albumin, immune globulin, clotting factor), number of heterosexual partners, homosexual activity in men, sexual contact with HBV carriers, tattooing, body piercing, acupuncture, occupational exposure to blood or body fluids, hemodialysis, HBV infection in the family, association with an institution for the developmentally disabled (institution associated), history of hospitalization, surgery, receipt of tissue or organ transplant, dental visit, incarceration and blood donation. For hepatitis C, potential risk factors collected include (in order by a mix of transmission efficiency, importance and other considerations): IDU, drug snorting, occupational exposure to blood or body fluids, blood transfusion, receipt of blood products (eg, albumin, immune globulin, clotting factor), hemodialysis, tattooing, body piercing, acupuncture, receipt of tissue or organ transplant, incarceration, sexual contact with $\mathrm{HCV}$ carriers, HCV infection in the family, association with an institution for the developmentally disabled (institution associated), history of hospitalization, surgery, dental visit, and blood donation. For acute $\mathrm{HBV}$ and acute $\mathrm{HCV}$ cases or unconfirmed cases, risk factor information both six months before the onset of the disease and lifetime risk factor information were collected, whereas for remote cases, only lifetime risk factor information was collected.

Data analysis: Data from all four health regions were combined and exported from Epi Info to a SAS database (12). Missing values and irregularities were checked and reassessed with the help of investigators of the health regions. Data processing and analysis were performed using SAS/STAT (13).

Unconfirmed hepatitis B cases were classified as either likely acute hepatitis B if patients had tested IgM anti-HBC positive regardless of clinical symptoms and elevated alanine aminotransferase/asparate aminotransferase, or likely remote hepatitis B if they had tested IgM anti-HBc negative or had not been tested for IgM anti-HBc. The confirmed acute and likely acute HBV cases were grouped together as 'acute' cases, while the remote and likely remote HBV cases were grouped together as 'remote' cases for analysis. For hepatitis $\mathrm{C}$, the remote and unconfirmed cases were analyzed together.

Incidence rate was calculated as the total number of identified acute and likely acute cases (for hepatitis B) or the total number of identified acute cases (for hepatitis C) over the total number of person-years under surveillance from October 1998 to December 1999 according to age group, sex and geographic region. For the analysis of potential risk fac- 
TABLE 1

Number of acute or likely acute hepatitis B and C, and incidence rate* in four health regions, 1998 to 1999

\begin{tabular}{|c|c|c|c|c|c|c|}
\hline \multirow[b]{2}{*}{ Age group (years) } & \multicolumn{3}{|c|}{ Hepatitis B } & \multicolumn{3}{|c|}{ Hepatitis C } \\
\hline & Male & Female & Total & Male & Female & Total \\
\hline Younger than 15 & $0(0.00)$ & $0(0.00)$ & $0(0.00)$ & $0(0.00)$ & $0(0.00)$ & $0(0.00)$ \\
\hline $15-29$ & $11(2.96)$ & $9(2.44)$ & $20(2.70)$ & $16(4.30)$ & $18(4.88)$ & $34(4.59)$ \\
\hline $30-39$ & $27(8.73)$ & $11(3.49)$ & $38(6.09)$ & $25(8.08)$ & $7(2.22)$ & $32(5.13)$ \\
\hline $40-59$ & $11(2.38)$ & $6(1.29)$ & $17(1.83)$ & $23(4.98)$ & $10(2.15)$ & $33(3.56)$ \\
\hline 60 and older & $3(1.40)$ & $1(0.36)$ & $4(0.81)$ & $3(1.40)$ & $0(0.00)$ & $3(0.61)$ \\
\hline Total & $52(3.01)$ & $27(1.52)$ & $79(2.25)$ & $67(3.88)$ & $35(1.97)$ & $102(2.91)$ \\
\hline
\end{tabular}

*Per 100,000 person-years in brackets

TABLE 2

Distribution of mutually exclusive risk factors for acute and likely acute hepatitis $B$ in four health regions, 1998 to 1999 , among those who were interviewed (56 of 79, 71\%)

\begin{tabular}{|c|c|c|c|}
\hline $\begin{array}{l}\text { Risk } \\
\text { factors }\end{array}$ & $\begin{array}{c}\text { Number } \\
\text { of } \\
\text { cases }\end{array}$ & $\begin{array}{c}\text { Percentage } \\
\text { of } \\
\text { all cases } \\
\end{array}$ & $\begin{array}{l}\text { Percentage of } \\
\text { cases with known } \\
\text { risk factors }\end{array}$ \\
\hline Injection drug use & 14 & 25.0 & 34.1 \\
\hline Drug snorting & 1 & 1.8 & 2.4 \\
\hline Blood product & 1 & 1.8 & 2.4 \\
\hline $\begin{array}{l}\text { Heterosexual } \\
\text { partners } \geq 2\end{array}$ & 10 & 17.9 & 24.4 \\
\hline $\begin{array}{l}\text { Men having sex } \\
\text { with men }\end{array}$ & 3 & 5.4 & 7.3 \\
\hline $\begin{array}{l}\text { Sex with hepatitis B } \\
\text { carriers }\end{array}$ & 5 & 8.9 & 12.2 \\
\hline $\begin{array}{l}\text { Hepatitis B carrier } \\
\text { in family }\end{array}$ & 1 & 1.8 & 2.4 \\
\hline Institution associated & 1 & 1.8 & 2.4 \\
\hline Hospitalization & 3 & 5.4 & 7.3 \\
\hline Surgery & 1 & 1.8 & 2.4 \\
\hline Dental visit & 1 & 1.8 & 2.4 \\
\hline Unknown & 15 & 26.8 & \\
\hline Total (exclude unknown) & 41 & & 100.0 \\
\hline Total (include unknown) & 56 & 100.0 & \\
\hline
\end{tabular}

tors, a ranking of the known potential risk factors was determined based on currently available epidemiological information. This includes results from the Sentinel Health Unit Surveillance from 1993 to 1995 in Canada (Centre for Infectious Disease Prevention and Control, unpublished data), Centers for Disease Control and Prevention hepatitis surveillance report (14), and data in the epidemiological literature for hepatitis $B(3,5,15)$ and hepatitis $C(4,6,16-19)$, respectively. According to the ranking (see ordered lists of risk factors in the previous section), a case was assigned to a single risk factor category if the patient reported a history of such a risk factor in the six months before the onset of the disease, regardless of a history of other risk factors that were ranked lower than this risk factor in the ranking.

\section{RESULTS}

Incidence rate: During the study period, of 1003 hepatitis B cases collected, 79 patients were identified as having acute $(n=69)$ or likely acute $(n=10)$ hepatitis $B$, resulting in an incidence rate of 2.3/100,000 person-years. Men had higher incidence rates than women (Table 1). The incidence peaked at age 30 to 39 years for both men and women (Table 1). The incidences in Calgary, Edmonton, Ottawa-Carleton and Winnipeg were 2.7, 2.7, 1.5 and 2.3/100,000 person-years, respectively. The remaining 924 cases were identified as remote $(n=909)$ or likely remote $(n=15)$ hepatitis B infections, resulting in an identification rate of $26.4 / 100,000$ person-years. Approximately $64.6 \%$ of the identified acute or likely acute hepatitis B cases were born in Canada, whereas $70.7 \%$ of the identified remote or likely remote hepatitis $\mathrm{B}$ cases were born in Asia.

Similarly, of 3049 hepatitis C cases collected, 102 were identified as acute hepatitis $\mathrm{C}$ cases, resulting in an incidence rate of 2.9/100,000 person-years. Men had higher incidence rates than women (Table 1 ). Incidence of acute hepatitis $C$ peaked at 30 to 39 years for men and 15 to 29 years for women (Table 1). The incidences in Calgary, Edmonton, Ottawa-Carleton and Winnipeg were 2.1, 6.0, 0.6, and $3.6 / 100,000$ person-years, respectively. The very large majority of the 3049 cases $(n=2947)$ were identified as remote $(n=2710)$ or unconfirmed $(n=237)$ hepatitis C infection, resulting an identification rate of $84.0 / 100,000$ person-years. About $84.3 \%$ of the identified acute hepatitis $C$ cases and $70.5 \%$ of the identified remote or unconfirmed hepatitis $\mathrm{C}$ cases were born in Canada.

Risk factors: Table 2 shows the distribution of the risk factors six months before the onset of the disease. Among 41 cases reporting one or more risk factors, 34\% $(n=14)$ reported a history of IDU, of which eight reported a history of sharing needles (57.1\%). A higher frequency of IDU history was reported among those who were 15 to 39 years of age $(43.3 \%)$, female (41.2\%) and born in Canada (42.4\%). None of the 41 cases could be attributed to a history of blood transfusion, occupational blood exposure, hemodialysis or organ transplant. Multiple heterosexual partners and sex with HBVinfected individuals accounted for $24 \%$ and $12 \%$ of all acute or likely acute hepatitis B cases, respectively. No acute or likely acute HBV cases were assigned to a history of tattooing, body piercing, acupuncture or incarceration six months before the onset of the illness. About $27 \%$ of the cases $(n=15)$ who were interviewed did not report any risk factors listed in the questionnaires. 
Table 3 shows the distribution of risk factors six months before the onset of the disease reported by acute hepatitis $\mathrm{C}$ cases. Among 57 cases that reported one or more risk factors, $63 \%(n=36)$ reported a history of IDU, of which $28(78 \%)$ shared needles. A higher frequency of IDU history was reported among those who were 15 to 39 years of age (71\%), female $(79 \%)$ and born in Canada (66\%). Drug snorting was associated with the transmission of HCV for $5.3 \%$ of the cases. One of the 57 cases reported a history of blood transfusion (see below in discussion). Heterosexual contact (ie, sex with $\mathrm{HCV}$ carriers) was a risk factor for $3.5 \%$ (two of 57 ) of the cases. None of the 57 cases was assigned to a history of the receipt of blood products, acupuncture, organ transplant, association with an institution or surgery. About $21 \%$ of all interviewed acute $\mathrm{HCV}$ cases $(n=15)$ reported no risk factors that could be associated with their infections.

Among the 2947 identified remote or unconfirmed hepatitis C cases, 1145 (39\%) were also interviewed for lifetime risk factor information. Among 1123 patients who reported at least one risk factor, approximately $56.3 \%(n=632)$ reported a history of IDU in their lifetime, and $6.9 \%(n=77)$ reported a history of drug snorting without IDU. A history of blood transfusion before 1990 or in or after 1990 was reported as a risk factor for $20.2 \%(n=227)$ and $4.6 \%(n=52)$, respectively, of these 1123 remote or unconfirmed hepatitis C cases. Other risk factors reported among the remote or unconfirmed cases included the receipt of blood products $(0.9 \%)$, occupational blood contact $(2.0 \%)$, hemodialysis $(0.1 \%)$, tattooing $(2.2 \%)$, body piercing $(1.9 \%)$, acupuncture $(0.4 \%)$, receipt of organ transplant $(0.1 \%)$, incarceration $(0.3 \%)$, history of sex with HCV carriers $(0.4 \%), \mathrm{HCV}$ carriers in family $(0.4 \%)$, history of hospitalization $(2.5 \%)$, and history of dental visit $(0.4 \%)$. None of the 1123 cases were assigned to a history of association with an institution or surgery. Only $2.2 \%(n=22)$ of the remote or unconfirmed cases reported no lifetime risk factor.

\section{DISCUSSION}

This enhanced surveillance covers provinces in central Canada and the Prairies, provinces with approximately $11 \%$ of the Canadian population. Both Ottawa-Carleton and Winnipeg health regions have English-speaking, as well as relatively large French-speaking populations, and all four health regions have a diversified ethnic composition. However, no health regions from the west coast, Quebec or the Atlantic region participated in this surveillance. According to available data, both hepatitis B and hepatitis C are more prevalent in British Columbia, whereas in the Atlantic region, the level of $\mathrm{HBV}$ and $\mathrm{HCV}$ infection may be lower than the national average.

The present surveillance was carried out using a predefined operating protocol and predefined questionnaires for all four health regions. Each health authority assigned one or more investigators to focus on this task. Furthermore, in all four health regions, nearly all of the testing for hepatitis B and $\mathrm{C}$ were performed by central or local public health labo-
TABLE 3

Distribution of mutually exclusive risk factors for acute hepatitis $C$ in four health regions, 1998 to 1999, among those who have been interviewed (72 of 102, 71\%)

\begin{tabular}{lccc}
\hline Risk & $\begin{array}{c}\text { Number } \\
\text { of } \\
\text { factors }\end{array}$ & $\begin{array}{c}\text { Percentage } \\
\text { of } \\
\text { all cases }\end{array}$ & $\begin{array}{c}\text { Percentage of } \\
\text { cases with known } \\
\text { risk factors }\end{array}$ \\
\hline Injection drug use & 36 & 50.0 & 63.2 \\
Drug snorting & 3 & 4.2 & 5.3 \\
Occupational blood & 2 & 2.8 & 3.5 \\
$\quad$ contact & 1 & 1.4 & 1.8 \\
Blood transfusion & 1 & 1.4 & 1.8 \\
Hemodialysis & 2 & 2.8 & 3.5 \\
Tattooing & 2 & 2.8 & 3.5 \\
Body piercing & 2 & 2.8 & 3.5 \\
Incarceration & 2 & 2.8 & 3.5 \\
Sex with hepatitis C & & & \\
$\quad$ carriers & 3 & 4.2 & 5.3 \\
Hepatitis C carrier & & & \\
$\quad$ in family & 1 & 1.4 & 1.8 \\
Hospitalization & 2 & 2.8 & 5.3 \\
History of dental visit & 15 & 20.8 & \\
Unknown & & & 100.0 \\
Total (exclude unknown) & 57 & 100.0 & \\
Total (include unknown) & 72 & & \\
\hline
\end{tabular}

ratories, or designated private laboratories. Therefore, it is reasonable to assume that the present surveillance captured most of the identified, clinically recognized acute hepatitis B and acute hepatitis $C$ cases.

Based on the incidence rates obtained from the present enhanced surveillance (2.3 and 2.9/100,000 person-years for acute hepatitis B and acute hepatitis C), an extrapolation to the whole population of Canada suggests that an estimated 706 and 911 cases of clinically recognized acute hepatitis B and acute hepatitis $C$, respectively, could be identified in Canada each year.

However, the incidence data from this surveillance and the above predicted national annual incidence can only serve as estimates regarding clinically recognized acute HBV and $\mathrm{HCV}$ infection. Due to the asymptomatic nature of hepatitis B and $\mathrm{C}$, the actual incidence of new HBV and HCV infection may be higher. If it is assumed that $50 \%$ of HBV infections (20) and $75 \%$ to $80 \%$ of $\mathrm{HCV}$ infections (4) are asymptomatic, approximately 1400 new HBV infections and 4500 new HCV infections may be occurring annually in Canada.

These are, nevertheless, conservative estimates, because not all acute cases would have been recognized and not all clinically recognized acute cases would have been identified by the present enhanced surveillance in the four health regions. Further, a certain percentage of identified hepatitis B or $\mathrm{C}$ cases could not be determined as acute or remote cases because of a lack of either clinical or laboratory information, or both. Some of those cases may be acute cases. However, the impact of this factor on hepatitis B should have been reduced by the inclusion of IgM anti-HBc-positive cases as likely acute hepatitis B cases. 
The case definitions used in this enhanced surveillance may have missed certain cases that were truly acute cases and misclassified certain cases as acute cases that were truly remote cases. For hepatitis B, the case definition used may be relatively sensitive and specific, although the addition of IgM anti-HBc positives may have an impact on specificity because not all IgM anti-HBc positive cases are acute cases. For hepatitis C, the case definition used may be less specific. Certain cases with symptoms and confirmed to be anti-HCV positive may have acquired $\mathrm{HCV}$ infection in the past but became symptomatic only recently.

The incidence rates obtained from the present enhanced surveillance project were compared with those obtained from the NNDR. Because the Calgary Health Authority and the Capital Health Authority of Edmonton cover most of the population in Alberta, data from these two regions were combined and compared with data from the NNDR in 1997 (21). The incidence rates of acute hepatitis B (per 100,000 person-years) from the enhanced surveillance and from NNDR are, 3.6 and 3.1 for men, 1.8 and 2.3 for women, and 2.7 and 2.7 for both sexes, respectively. For acute hepatitis C, the incidence rates (per 100,000 person-years) are 5.0 and 70.4 for men, 3.2 and 46.4 for women, and 4.1 and 58.5 for both sexes, respectively. The incidence rates of acute hepatitis B obtained from the NNDR are comparable with those obtained from the present enhanced surveillance project, probably reflecting the fact that the diagnosis of acute hepatitis B is less problematic than that of acute hepatitis C, and only a small proportion of HBV infection become chronic. Furthermore, risk factor information is not available yet from NNDR. The incidence rates of hepatitis C from the NNDR are remarkably higher than those from the enhanced surveillance project. Due to the nature of the infection and the lack of effective diagnostic methods to differentiate acute from chronic infections, it appears that most of the reported hepatitis C cases through the NNDR were remote infections. The incidence rate for acute hepatitis $\mathrm{C}$ determined from the enhanced surveillance project should be more reliable.

The incidence rate for hepatitis B was similar for the four regions. However, the hepatitis $C$ numbers varied considerably, perhaps a reflection of a different rate of IDU in the underlying population, although definite data are lacking. Other unrecognized factors may also contribute to the regional variation.

Bias may have been introduced in the results of risk factors because not all cases were interviewed for risk factor information. Most of the chronic hepatitis B cases who were not interviewed were most likely to be immigrants from endemic areas. For the acute hepatitis B and acute hepatitis C group, the patients who were not interviewed could be overrepresented by persons at a higher risk of HBV or HCV infection. For example, injection drug users or persons with risky sexual behaviours may not have been interviewed because of their lack of permanent address and tendency to migrate from one place to another. Therefore, the percentage of IDU and that of risky sexual behaviours among the acute cases identified may be underestimates.

In the present enhanced surveillance project, about $27 \%$ of interviewed acute hepatitis B cases and $21 \%$ of interviewed acute hepatitis $C$ cases did not report any potential risk factors. Of the interviewed hepatitis B cases with no reported risk factors, $40 \%$ were born in Asia. However, no such pattern was observed among the interviewed hepatitis $C$ cases with no reported risk factors. It is possible that some potential risk factors have not been identified or recognized, and therefore, have not been listed in the questionnaires for data collection. Alternatively, some patients might have forgotten a history of risk factors or denied social behaviours that are stigmatized.

The present enhanced surveillance project for hepatitis B and hepatitis $\mathrm{C}$, as with other similar surveillance programs operated elsewhere (22-25), provides an effective means to identify acute hepatitis B and acute hepatitis C cases, and to evaluate risk factors associated with the transmission of these diseases. This information is fundamental to decisionmaking for the prevention and control of the two diseases. Data from this surveillance clearly show that both hepatitis B and hepatitis $\mathrm{C}$ are important public health threats to Canadians. IDU is documented as the most frequent single risk factor associated with both types of infections, whereas sexual transmission contributes significantly to the transmission of hepatitis B. Prevention strategies for both diseases should focus on IDU, especially in people aged 15 to 39 years. Drug snorting as a possible important risk factor associated with acute hepatitis $C$ infection should be addressed in further studies. Furthermore, hepatitis B vaccination has proven to be effective in prevention of HBV transmission $(26,27)$. Preventive strategies aimed at reducing risky heterosexual behaviours and homosexual practices are warranted.

ACKNOWLEDGEMENTS: The work was initiated by Dr Paul Gully at the Centre for Infectious Disease Prevention and Control, and encouraged and supported by provincial and territorial health authorities. Dr John Spika of Centre for Infectious Disease Prevention and Control, and many provincial and territorial epidemiologists provided valuable support and advice to this surveillance. Without their effort and support, this work would not have been possible.

\section{REFERENCES}

1. Tepper ML, Gully PR. Hepatitis B. CMAJ 1997;156:1033-4.

2. Remis R, Hogg R, Krahn MD, Preiksaitis JK, Sherman M. Estimating the number of blood transfusion recipients infected by hepatitis C virus in Canada, 1960-85 and 1990-92. Ottawa: Health Canada, 1998.

3. Tepper ML, Gully PR. Lovers and livers: hepatitis B as an STD. Can J Hum Sex 1997;6:135-42.

4. Gully PR, Tepper ML. Hepatitis C. CMAJ 1997;156:1427-30.

5. Roy E, Haley N, Lemire N, Boivin JF, Leclerc P, Vincelette J. Hepatitis B virus infection among street youths in Montreal. CMAJ 1999;161: 689-93.

6. Delage G, Infante-Rivard C, Chiavetta JA, Willems B, PI D, Fast $M$. Risk factors for acquisition of hepatitis $C$ virus infection in blood donors: Result of a case-control study. Gastroenterology 1999;116:893-9. 
7. Sockett PN, Garnett MJ, Scott C. Communicable disease surveillance: notification of infectious disease in Canada. Can J Infect Dis 1996;7:293-5.

8. Alter MJ. Epidemiology of hepatitis C. Hepatology 1997;26:62S-5S.

9. Global surveillance and control of hepatitis C. Report of a WHO Consultation organized in collaboration with the Viral Hepatitis Prevention Board, Antwerp, Belgium. J Viral Hepat 1999;6:35-47.

10. Hepatitis C-Prevention and control: A public health consensus. Ottawa, Canada, October 14-16, 1998. Can Commun Dis Rep 1999;25S2:1-27.

11. Centers for Disease Control and Prevention. Creating Questionnaires using EPED. EPI INFO 6.04b Manual. Atlanta: Centers for Disease Control and Prevention, 1997.

12. SAS Language Reference Dictionary, Version 7-1, Volume 1. Cary: SAS Institute Inc, 1999:1-980.

13. SAS Institute Inc. SAS/STAT User's Guide, Version 7-1, Volume 3. Cary: SAS Institute Inc, 1999:1203-312.

14. Centers for Disease Control and Prevention. Hepatitis Surveillance Report No. 56, 1996. Atlanta: Centers for Disease Control and Prevention, 1996.

15. Gresens CJ, Holland P. Current risks of viral hepatitis from blood transfusions. J Gastroenterol Hepatol 1998;13:443-9.

16. Neal KR, Jones DA, Killey D, James V. Risk factors for hepatitis $\mathrm{C}$ virus infection. A case-control study of blood donors in the Trent Region (UK). Epidemiol Infect 1994; 112:595-601.

17. Shimokura GH, Gully PR. Risk of hepatitis C virus infection from tattooing and other skin piercing services. Can J Infect
Dis $1995 ; 6: 235-8$.

18. Woodfield GD, Harness M, Rix-Trott K. Hepatitis C virus infections in oral and injectable drug users. $\mathrm{N} \mathrm{Z}$ Med J 1993;106:332-4.

19. Murphy EL, Bryzman SM, Glynn SA, et al. Risk factors for hepatitis $C$ virus infection in United States blood donors. Hepatology 2000;31:756-62.

20. Laboratory Centre for Disease Control. Canadian Immunization Guide, Fifth Edition, 1998. Ottawa: Health Canada, 1998:90.

21. Division of Disease Surveillance. Notifiable Disease On-Line Centre for Infectious Disease Prevention and Control, Health Canada. Ottawa: Health Canada, 1999.

22. Massari V, Maison P, Desenclos J-C, Flahault A. Six years of sentinel surveillance of hepatitis B in general practice in France. Eur J Epidemiol 1998;14:765-7.

23. Balogun MA, Ramsay ME, Fairley CK, Collins M, Heptonstall J. Acute hepatitis B infection in England and Wales: 1985-1996. Epidemiol Infect 1999;122:125-31.

24. Andrews R, Curran M. Enhanced surveillance for incident cases of hepatitis C in Australia, 1995. Commun Dis Intell 1996;20:384-8.

25. Ramsay ME, Balogun MA, Collins M, Balraj V. Laboratory surveillance of hepatitis $C$ virus infection in England and Wales: 1992 to 1996. Commun Dis Public Health 1998;1:89-94.

26. Tepper ML. Universal hepatitis B immunization: young adolescent immunization. Vaccine 1998;16:S23-6.

27. Mahoney FJ, Smith N, Alter MJ, Margolis H. Progress towards the elimination of hepatitis B virus transmission in the United States. Viral Hepatitis 1997;3:105-19. 


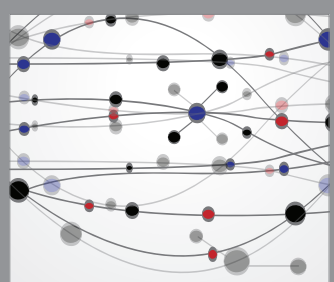

The Scientific World Journal
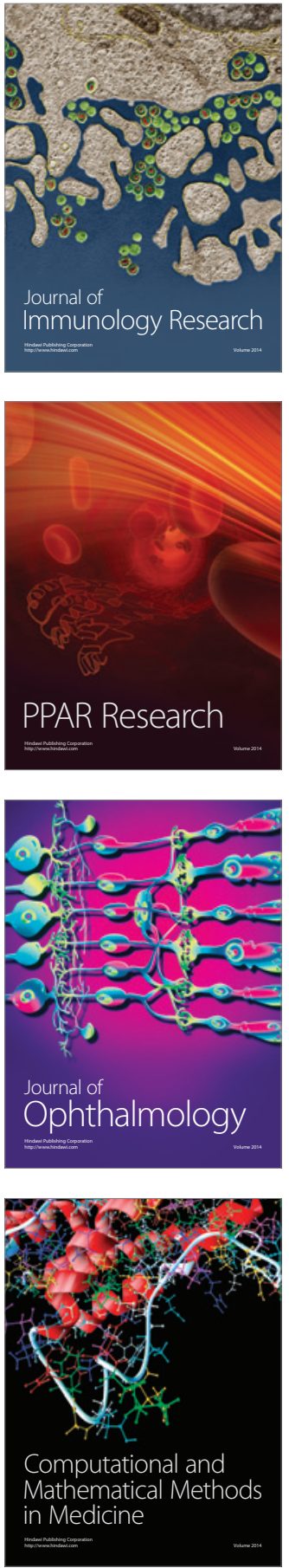

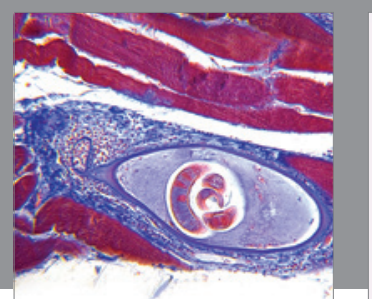

Gastroenterology Research and Practice

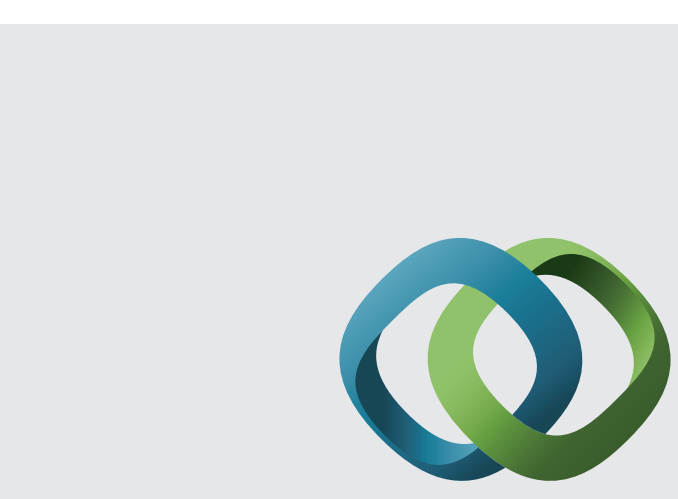

\section{Hindawi}

Submit your manuscripts at

http://www.hindawi.com
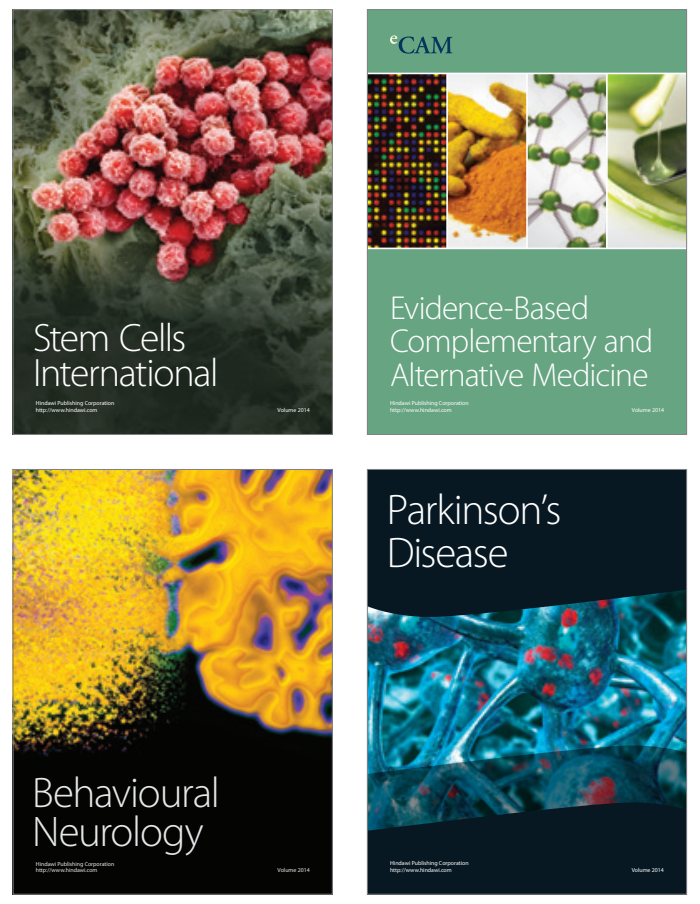
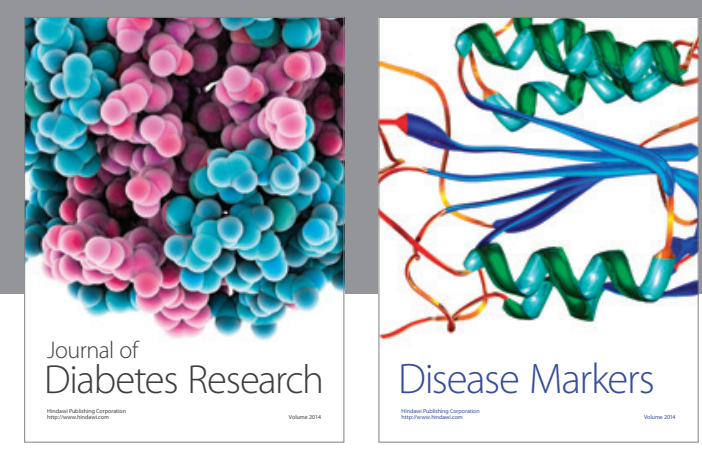

Disease Markers
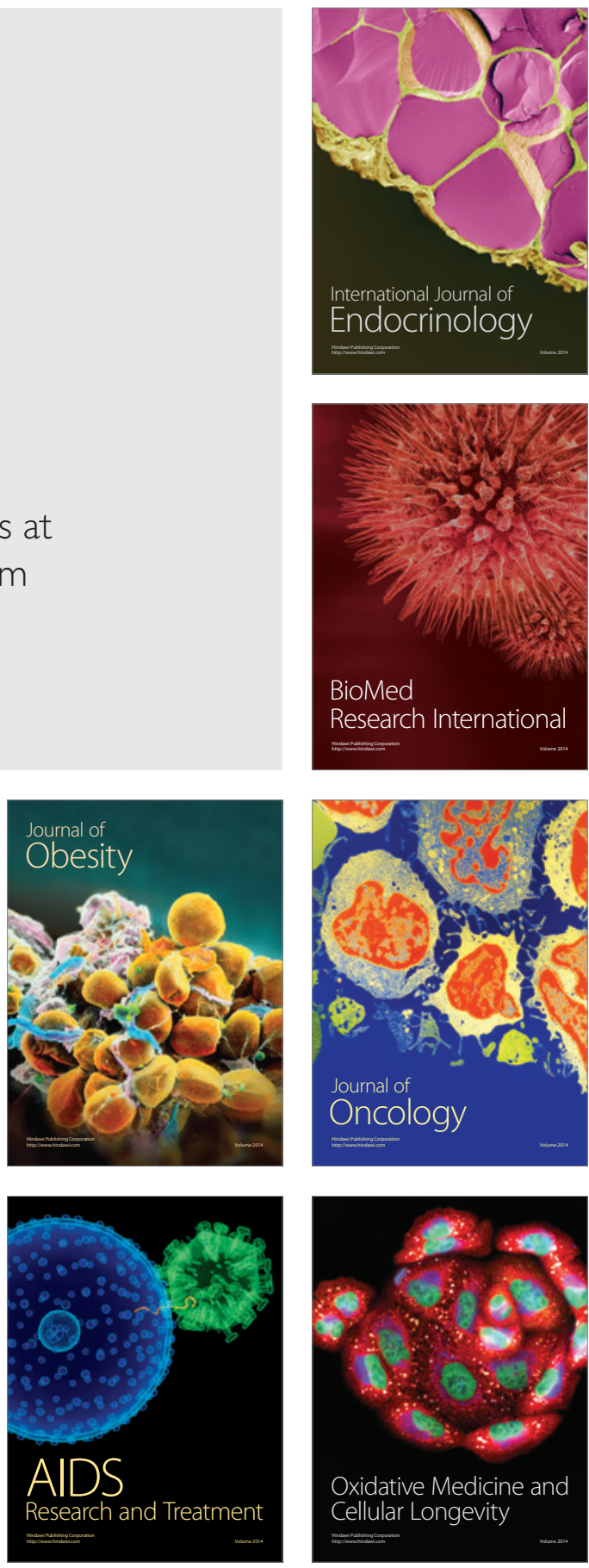